\title{
A case series on conservative management in pregnancies with abnormal placentation in obstetrics: placenta accrete, increta and percreta
}

\author{
Fasiha Tasneem*, Vijayalakshmi Shanbhag
}

Department of Obstetrics and Gynecology, SCGMC, Nanded, Maharashtra, India

Received: 09 October 2018

Accepted: 01 November 2018

*Correspondence:

Dr. Fasiha Tasneem,

E-mail: fasiha.aziz@yahoo.com

Copyright: () the author(s), publisher and licensee Medip Academy. This is an open-access article distributed under the terms of the Creative Commons Attribution Non-Commercial License, which permits unrestricted non-commercial use, distribution, and reproduction in any medium, provided the original work is properly cited.

\begin{abstract}
Adherent placenta is one of the important causes of post- partum hemorrhage. Placenta accreta-related pathologies are an increasing contributor to maternal death from hemorrhage. With the rising caesarean delivery rate the incidence of placenta accreta has significantly increased. Morbidly adherent placenta (MAP) occurs when there is a defect in the decidua basalis, resulting in an abnormal invasion of the placenta into the substance of the uterus. A multidisciplinary approach is relevant in managing these patients in order to reduce morbidity and mortality associated with morbidly adherent placenta. A non-surgical conservative method is to leave the placenta in situ to reabsorb and institute treatment with chemotherapeutic agents, such as methotrexate. With improvement in the medical services conservative management for adherent placenta has gained significance.
\end{abstract}

Keywords: Methotrexate, Morbidly adherent placenta, Placenta accrete

\section{INTRODUCTION}

Adherent placenta is one of the important causes of postpartum hemorrhage. Placenta accreta-related pathologies are an increasing contributor to maternal death from hemorrhage. ${ }^{1}$ With the rising caesarean delivery rate the incidence of placenta accreta has significantly increased. ${ }^{2}$ Morbidly adherent placenta (MAP) occurs when there is a defect in the decidua basalis, resulting in an abnormal invasion of the placenta into the substance of the uterus. ${ }^{3}$ When this condition is not anticipated and attempts are made to deliver the placenta there can be catastrophic hemorrhage resulting in maternal mortality. Though the mortality due to placenta accreta has fallen from the early 20th century, the incidence of adherent placenta has increased from $0.025 \%$ in $1970 \mathrm{~s}$ to $0.04 \%$ in $1990 \mathrm{~s}{ }^{4}$ Morbidly adherent placentation may be suspected when there is a placenta praevia in a woman with a history of caesarean section or other uterine surgery. ${ }^{5}$ The term placenta accreta is used to describe any placental implantation that is adherent firmly to the uterine wall. Placental villi are anchored to the myometrium due to defective decidualization.

If villi invade the myometrium, the condition is called placenta increta. If the invasion goes as deep as reaching the serosal surface, this is called placenta percreta. If the placenta is thought to be low lying (less than $20 \mathrm{~mm}$ from the internal os) or praevia (covering the os) at the routine fetal anomaly scan, a follow-up ultrasound examination including a TVS is recommended at 32 weeks of gestation to diagnose persistent low-lying placenta and/or placenta praevia. ${ }^{6}$ Placenta percreta is associated with a maternal mortality as high as $10 \%$ and significant maternal morbidity. ${ }^{7}$ Uterine perforation and rupture into the urinary bladder are potential complications. ${ }^{8}$ The reduction in mortality is mainly because of early diagnosis and changing trends in management especially expectant and medical methods with the availability of more sophisticated radiological investigations. 


\section{CASE REPORT}

\section{Case 1: A case of placenta percreta}

A 24-year-old female G2P1L1 with previous LSCS done 3 yrs back with 24.6-week gestational age by her LMP came to obstetric casualty with c/o bleeding per vagina for 6 hours. The bleeding was painless and causeless. There were no $\mathrm{h} / \mathrm{o}$ similar episodes of bleeding in the past. On examination, patient was pale but haemodynamically stable, size of uterus corresponded to 22-24 week, FHS not heard by Doppler and local examination showed minimal bleeding. She was started with intravenous tranexamic acid, injectable antibiotics and blood transfusion Ultrasound showed placenta praevia with placenta covering the internal os completely with multiple irregular lacunae of varying sizes seen within the placenta with accrete. There was no improvement in the patient with conservative management and there another active bout of bleeding. The decision for termination of pregnancy with conservation of uterus was made and possibility of obstetric hysterectomy explained to the patient and relatives.

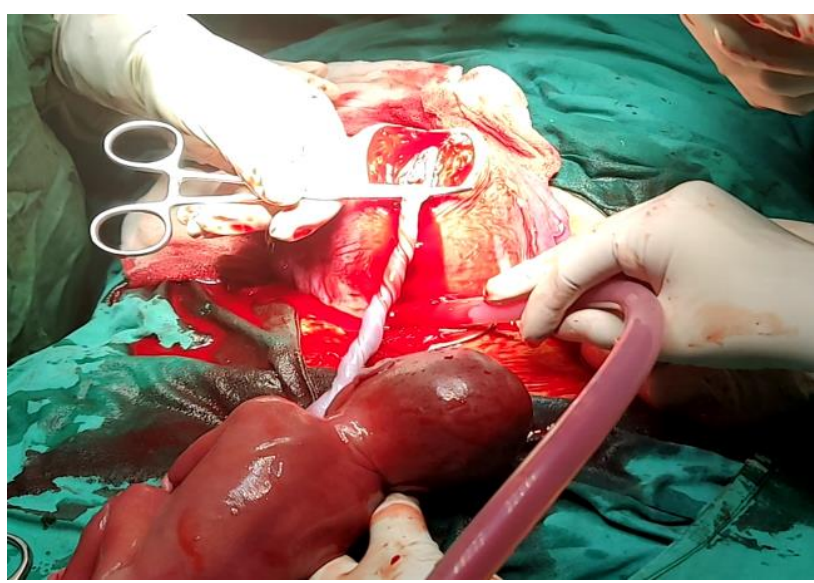

Figure 1: Classical cesarean section done with vertical incision over the fundus and baby delivered.

Prophylactic b/l internal iliac artery ligation done followed by classical cesarean section. There was invasion of placenta through the serosa of the uterus reaching up to the bladder indicating placenta percreta. 24-week IUD baby was delivered, and placenta left in situ. Uterus closed in two layers. Hemostasis achieved. Patient was given 2-pint blood transfusion intra operatively and 3-pint blood transfusion and 4-pint FFP post operatively. Patient was given inj methotrexate at the dose of $1 \mathrm{mg} / \mathrm{kg}$ on post op day 3. Patient had bleeding per vagina for 15 days and patient was discharged on post op day 17. Patient came with c/o pv bleeding on post op day 24 and passed mass per vagina which was found to be a placental cotyledon. Beta HCG level was done and was $117 \mathrm{~m} \mathrm{IU} / \mathrm{ml}$ and was repeated one week later it was $82 \mathrm{~m} \mathrm{IU} / \mathrm{ml}$. Patient was followed up with serial beta
HCG levels which showed a decreasing trend and serial USG with Doppler (Figure 1 and 2).

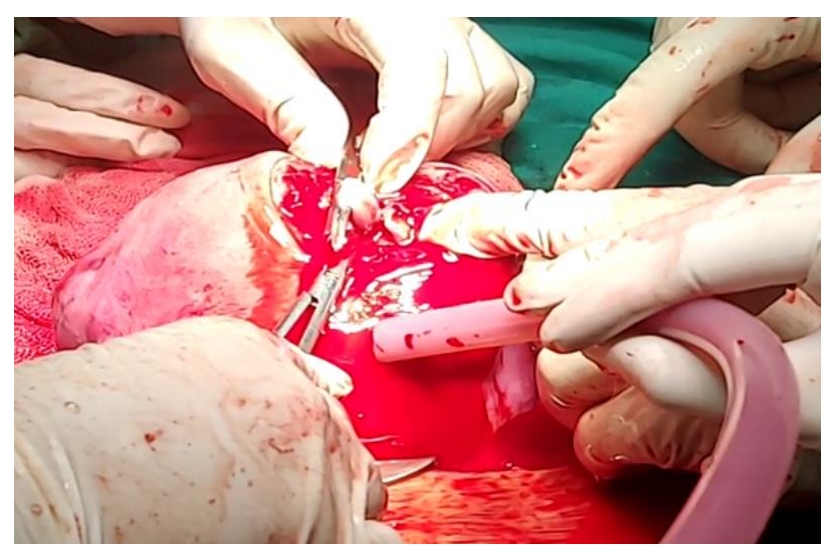

Figure 2: Cord tied and placenta left in situ without any attempt of removing the placenta.

\section{Case 2: A case of placenta increta}

A 25-year-old female G5P3L3A1 with prev 3 LSCS with 31 weeks pregnancy came to obstetrics casualty with c/o bleeding per vagina. Ultrasound examination of the patient showed low lying placenta completely covering the internal os with loss of interface between the placenta and myometrium suggestive of global placenta accrete, scar thickness $6 \mathrm{~mm}$.

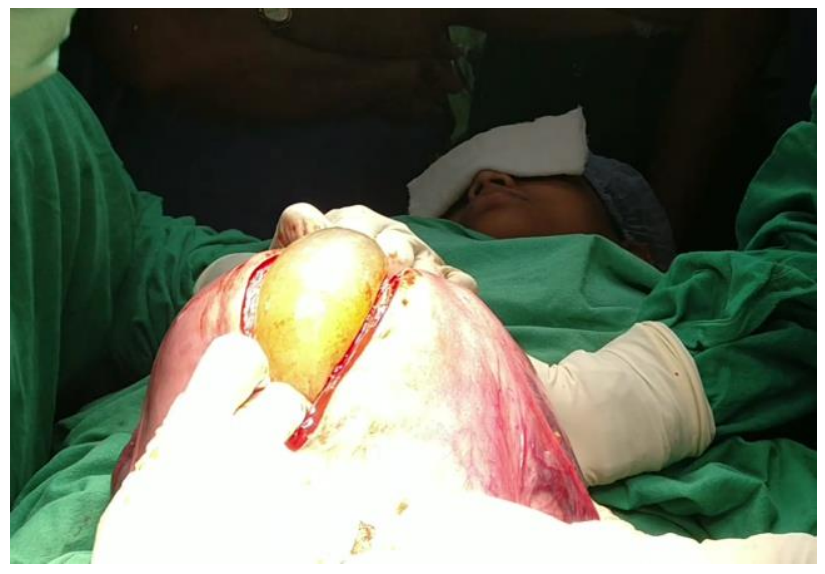

Figure 3: Classical cesarean section with vertical incision over the fundus of uterus taken.

On examination patient was haemodynamically stable, size of the uterus corresponded to $30 \mathrm{wk}$ of gestation, FHS present 136 beats $/ \mathrm{min}$, local examination showed minimal bleeding. Patient was admitted in the hospital and managed conservatively till 37-week of gestation. She had two similar episodes of bleeding pv during her stay in the hospital. 2-pint blood transfusion was given. At 37-week of gestation patient was posted for classical caesarean section and consent for possible obstetric hysterectomy was taken. Classical caesarean section was done and a healthy male baby weighing $3.5 \mathrm{~kg}$ delivered. 


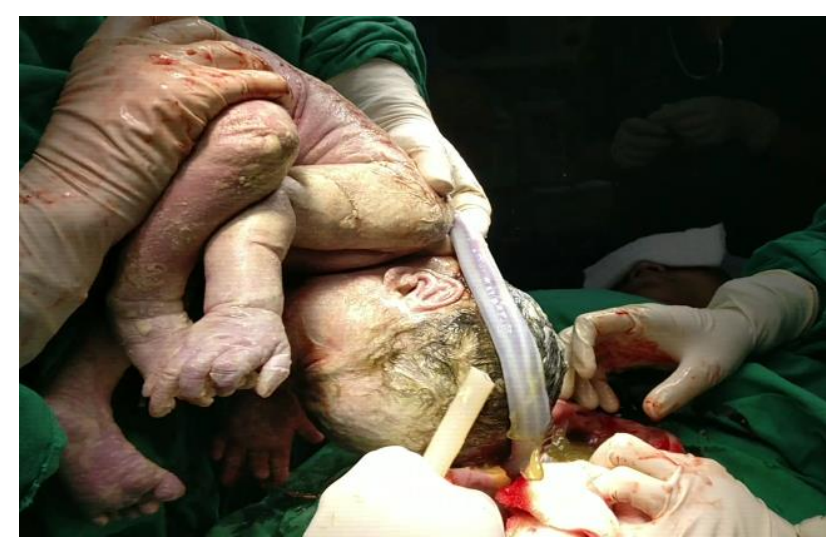

Figure 4: A full term male child delivered by classical cesarean section.

B/l internal iliac artery ligation done. No attempt was made for placental separation and placenta left in situ. Uterus closed in two layers and haemostasis achieved. 2pint Blood transfusion was done intra op and 3-pint blood transfusion and 6-pint FFP transfusion done post operatively.

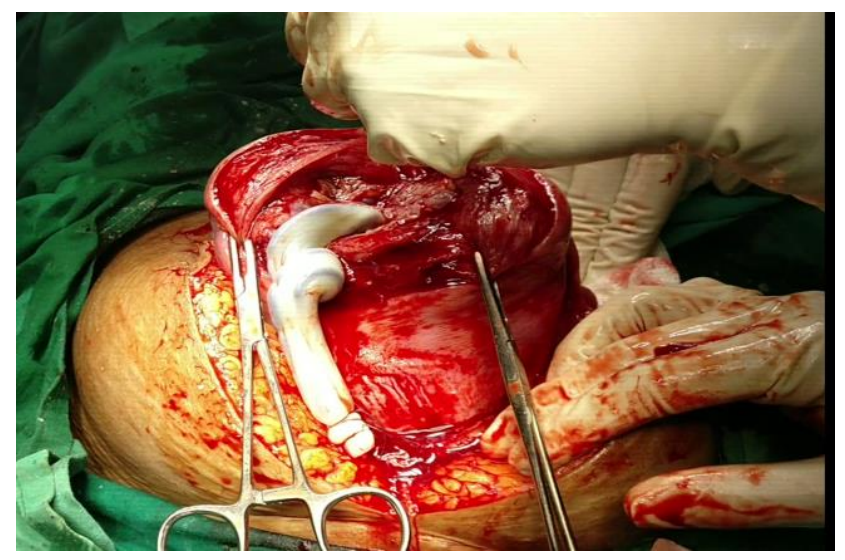

Figure 5: Cord tied and placenta left in situ.

Patient was given Inj methotrexate $1 \mathrm{mg} / \mathrm{kg}$ on post op day 3 to facilitate autolysis of placenta.

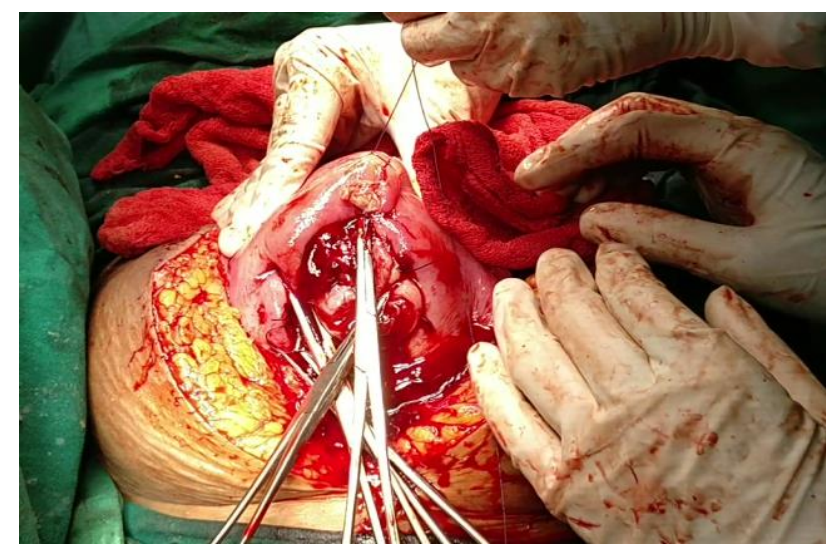

Figure 6: Uterus closed in layers with placenta left in situ.
She had episodes of heavy pv bleeding twice during her stay in hospital. Patient was discharged on post op day 21 with healthy wound of caesarean section and counseled regarding the contraception and seek help immediately in case of bleeding pv. On $16^{\text {th }}$ post op day uterine artery Doppler showed RI of 0.6 in both left and right uterine arteries and PI of 1.7 in left uterine artery and 1.51 in right uterine artery. On post op day 24 uterine Doppler showed RI 0.65 in left uterine artery and 0.57 in right uterine artery, and PI of 0.89 in left uterine artery and 0.78 in right uterine artery. She was followed up with serial Ultrasound and uterine artery doppler for next 3 months. Placenta was completely autolysed by 3 months. Patient had an excellent recovery and came for follow up in OPD after one year for laproscopic tubal ligation (Figure 3-7).

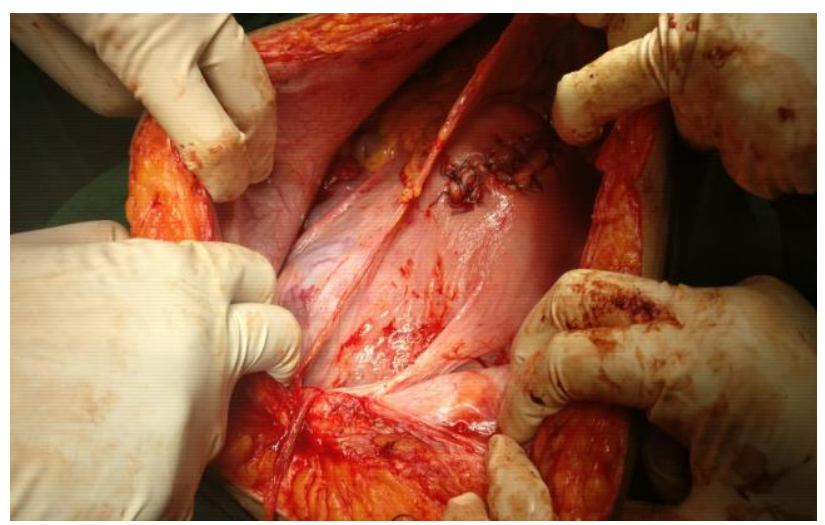

Figure 7: Following closure of uterus after conservative management of adherent placenta.

\section{Case 3: A case of placenta accrete}

A 25-year-old female G3P2L2 with prev 2 LSCS with 22-week pregnancy came to emergency room with c/o bleeding pv. Patient was haemodynamically stable and uterus corresponded to 22-week gestation with positive test for external ballotment. Ultrasound examination showed low lying placenta covering the internal os with adherent placenta at scar site s/o placenta accrete. Patient was managed conservatively and discharged against medical advice after 3 days. Patient came to obstetric casualty after one week with c/o excessive bleeding pv and in a state of shock. Her pulse was 126 beats per minute, BP $80 / 60 \mathrm{~mm}$ of $\mathrm{Hg}$ with severe pallor. Two-pint blood transfused immediately and decision of emergency hysterotomy was done. Emergency laparotomy with b/l internal iliac artery ligation was done. Hysterotomy was done with transverse incision taken over lower part of upper uterine segment. A 22-week foetus was delivered and placenta left in situ. Uterus closed in layers. 2 Pint blood and 6-pint FFP transfusion done intra op and 6-pint blood transfusion given post op. Inj Methotrexate was delayed till blood counts were normal and given on post op day 6. Patient was discharged on day 12 without any complaints. She was followed up with serial ultrasound and beta HCG. Patient never had c/o excessive bleeding 
pv during the recovery period and recovered well. Placenta was completely autolysed in a span of 3 months.

\section{DISCUSSION}

A multidisciplinary approach is relevant in managing these patients in order to reduce morbidity and mortality associated with morbidly adherent placenta. Treatment for placenta percreta is primarily surgical, with hysterectomy being the treatment of choice in $93 \%$ of all cases. ${ }^{9}$ Various modifications of the uterine incision to avoid the placenta have been reported. Classical incision, high transverse incision, fundal incision, fundal transverse incision has all been used. A non-surgical conservative method is to leave the placenta in situ to reabsorb and institute treatment with chemo- therapeutic agents, such as methotrexate. ${ }^{10}$ Methotrexate, a folate antagonist, acts primarily against rapidly dividing cells, and therefore is effective against dividing trophoblast. In a case study conducted by Das et al, treatment of placenta accreta with methotrexate, Injection methotrexate was administered on the $16^{\text {th }}$ day following the regime of 1,3 , 5 and 7 with injection folinic acid on alternate days. ${ }^{11}$ Methotrexate has been used in varying doses and routes, however, there are no randomized trials and no standard protocol regarding its dosage. ${ }^{12}$

Washecka et al carried out a meta-analysis of 54 reported cases of placenta percreta. They noted that $31 \%$ of cases presented with haematuria. ${ }^{13}$ In a case report of a case of placenta percreta by Mohan $\mathrm{P}$ et al had subtotal obstetric hysterectomy done for the case of placenta percreta and intraoperative blood loss was approximately 3.3 litres which was replaced with transfusion of 8 units of whole blood, 3 units of fresh frozen plasma and 2 units of platelet concentrates during the per-operative and postoperative period. ${ }^{14}$ Morbid adhesion of placenta should be suspected even in women without any risk factors when there is postpartum hemorrhage and the same should be ruled by performing an immediate Ultrasonogram.

MRI is the best modality for confirmation of placenta accreta and increta. Medical management with methotrexate should be preferred over expectant management when there are no contraindications. This is essential to preserve the uterus for future fertility.

\section{CONCLUSION}

Abnormalities of placenta are one of the major factors affecting maternal and fetal outcome in obstetrics. Availability of excellent drugs like methotrexate aid in the conservative management facilitating autolysis of the placenta left in situ. With improvement in the medical services conservative management for adherent placenta has gained significance.
Funding: No funding sources

Conflict of interest: None declared

Ethical approval: Not required

\section{REFERENCES}

1. Knight M, Callaghan WM, Berg C, Alexander S, Bouvier-Colle MH, Ford JB, et al. Trends in postpartum hemorrhage in high resource countries: a review and recommen- dations from the International Postpartum Hemorrhage Colla- borative Group. BMC Pregnancy Childbirth. 2009;9:55.

2. Miller DA, Chollet JA, Goodwin TM. Clinical risk factors for placenta previa-placenta accreta. Am J Obstet Gynecol. 1997;177(1):210-4.

3. Herath RP, Wijesinghe PS. Management of morbidly adherent placenta. Sri Lanka J Obstet Gynaecol. 2012;33(2)39-44.

4. Miller DA, Chollet JA, Goodwin TM. Clinical risk factors for placenta previa, placenta accreta. Am J Obstet Gynecol. 1997;177:210-4.

5. Armstrong CA, Harding S, Matthews T, Dickinson JE. Is placenta accreta catching up with us? ANZJOG. 2004;77(3):210-31.

6. RCOG Greentop guidelines. DOI: 10.1111/14710528.15306 .

7. Morken NH, Henriksen H. Placenta percreta - two cases and review of the literature. Eur J Obstet Gynecol Reprod Biol. 2001;100:112-5.

8. Khong TY. The pathology of placenta accreta, a worldwide epidemic. J Clin Pathol. 2008;61:1243-6.

9. Levine D, Hulka CA, Ludmir J, Li W, Edelman RR. Placenta accreta: Evaluation with color Doppler US, power Doppler US, and MR imaging. Radiol. 1997;205:773-6.

10. Maldjian C, Adam R, Pelosi M, Pelosi M, Rudelli RD, Maldjian J. MRI appearance of placenta percreta and placenta accreta. Magn Reson Imag. 1999;17:965-71.

11. Das SS, Devi LS, Singh LR, Singh R. Conservative management of placenta accreta with injection methotrexate to preserve fertility. J Med Soc. 2014;28:125-7.

12. Morken NH, Kahn JA. Placenta accreta and methotrexate treat- ment. Acta Obstet Gynecol Scand. 2006;85:248-50.

13. Washecka R, Behling A. Urologic complications of placenta percreta invading the urinary bladder. a case report and review of the literature. Hawaii Med J. 2002;61(4):66-9.

14. Mohan P, Bajwa S, Sharma S, Kaur P. Placenta percreta-an obstetrician's nightmare. Sri Lanka J Obstet Gynaecol. 2012;32(2):39-40.

Cite this article as: Tasneem F, Shanbhag V. A case series on conservative management in pregnancies with abnormal placentation in obstetrics: placenta accrete, increta and percreta. Int J Reprod Contracept Obstet Gynecol 2018;7:5193-6. 